\title{
Properties of a Bacillus subtilis Mutant Able to Sporulate Continually During Growth in Synthetic Medium
}

\author{
By TAKAKAZU ENDO, HIRO-O ISHIHARA AND ERNST FREESE* \\ Laboratory of Molecular Biology, National Institute of Neurological and Communicative \\ Disorders and Stroke, National Institutes of Health, Building 36, Room 3DO2, Bethesda, \\ Maryland 20205, U.S.A.
}

(Received 23 February 1982; revised 6 May 1982)

\begin{abstract}
Several mutants of Bacillus subtilis were isolated which sporulate continually during exponential growth in glucose medium. The spdAl mutation, responsible for the continual sporulation of one of the mutants, mapped near thr. When an exponentially growing culture of a strain containing spdAl was maintained at essentially constant turbidity, $5 \%$ of the viable cells contained heatresistant spores. The continual sporulation depended on the stringent response since it was absent in spdA relA double mutants. Genetic and biochemical analysis indicated that the continual sporulation of $s p d A l$ strains was associated with a lower specific activity of pyruvate carboxylase, which limited the rate of oxaloacetate synthesis from glucose via pyruvate and thereby the supply of compounds depending on the citrate cycle, especially aspartate. Therefore, the mild stringent response caused by the spdA1 mutation seems to result from a partial deficiency of aspartyl-tRNA which may exert its sporulation-initiating effect during a limited time interval in each growth cycle. A mutant blocked in fumarase activity (citG) behaved similarly. It grew only slowly in glucose medium because much of the limiting oxaloacetate was wasted for the excretion of fumarate. The mutant produced little aspartate and sporulated at a high frequency in glucose medium, even in the presence of glutamate; the sporulation was again prevented by aspartate or malate or by introduction of the relA marker into the strain.
\end{abstract}

\section{INTRODUCTION}

Sporulation of Bacillus subtilis is usually studied under conditions where most cells enter the sporulation development within a time span of less than $1 \mathrm{~h}$. Such conditions occur automatically at the end of growth in certain (sporulation) media; they can be initiated by the transfer of cells from a rich to a poor growth medium, and they can be induced by the addition of inhibitors of purine synthesis or by the use of auxotrophs causing partial deprivation of guanine nucleotides. The onset of this massive sporulation was found to be correlated with a decrease in the concentration of GTP (and GDP), whereas other nucleotides increased under some sporulation conditions and decreased under other sporulation conditions (Lopez et al., 1979; Freese, 1981; Freese et al., 1981). The transfer of cells from a rich to a poor medium results in a (transient) deficiency of amino acids which produces the stringent response encompassing the increase of two highly phosphorylated guanine nucleotides and the decrease in the synthesis of RNA and other macromolecules (Gallant, 1979). Relaxed (relA) mutants have been used to demonstrate that the stringent response is not necessary for sporulation, e.g. in nutrient sporulation medium (Rhaese \& Groscurth, 1976; Nishino et al., 1979; Lopez et al., 1981a). However, other conditions of nutrient deprivation, such as the step-down from a medium containing most amino acids to one containing only glutamate (Sterlini \& Mandelstam, 1969), or partial deprivation of any one amino acid, cause sporulation by evoking the stringent response, which includes the decrease in GTP concentration (Lopez et al., 1981 a, b; Ochi et al., 1981).

In certain media which enable only slow growth, a small fraction of cells can continually enter the sporulation development process at a frequency that depends on the composition of the 
medium; this was shown in cultures whose turbidity (Schaeffer et al., 1965) or growth-limiting supply of a nutrient (Dawes \& Mandelstam, 1970) was kept essentially constant. The biochemical mechanism of this sporulation control has not been studied; it may be related to the fact that sporulation can be initiated by the stringent response to partial amino acid deprivation (Ochi et al., 1981).

Several mutants have been reported which can sporulate in a medium containing excess glucose (Kunst et al., 1974; Takahashi, 1979). It is not clear from the literature, however, whether this sporulation occurred continually or only after the end of growth; the latter would indicate that the depletion or accumulation of some compound may cause this sporulation. We have obtained several strains that produce high spore titres in synthetic medium containing excess ammonium, glucose and phosphate, in which the standard and most other strains of $B$. subtilis produce only few spores. The mutant cells enter into sporulation not only after the end of growth but at a high frequency throughout exponential growth. Because this continual sporulation can be prevented by the addition of glutamate or other compounds associated with the citrate cycle, the cause of this phenomenon can be studied in more depth. We describe here the genetic and biochemical properties of one of these mutations (termed spdAl). The continual sporulation caused by the $s p d A$ mutation was limited to $\left(\mathrm{rel}^{+}\right)$strains showing the stringent response. Our results demonstrate that an enzyme change which is so minor that it does not noticeably affect cell growth can have a major effect on differentiation.

\section{METHODS}

Organisms, media and spore titre. The strains of $B$. subtilis used are Hsted in Table 1 . Synthetic medium contained $10 \mathrm{mM}-\left(\mathrm{NH}_{4}\right)_{2} \mathrm{SO}_{4}, 5 \mathrm{mM}$-potassium phosphate buffer $(\mathrm{pH} 7.0), 100 \mathrm{mM}$-morpholinopropanesulphonate $(\mathrm{pH}$ adjusted to 7.0 by KOH), $2 \mathrm{mM}-\mathrm{MgCl}_{2}, 0.7 \mathrm{mM}-\mathrm{CaCl}_{2}, 50 \mu \mathrm{M}-\mathrm{MnCl}_{2}, 5 \mu \mathrm{M}-\mathrm{FeCl}_{3}, 2 \mu \mathrm{M}$-thiamin. $\mathrm{HCl}, 1 \mu \mathrm{M}-\mathrm{ZnCl}_{2}$, $20 \mu \mathrm{g} \mathrm{L}$-methionine $\mathrm{ml}^{-1}$ and $50 \mu \mathrm{g} \mathrm{L}$-tryptophan $\mathrm{ml}^{-1} ; 55 \mathrm{mM}$-D-glucose (glucose medium) or other carbon sources were added as stated. Nutrients required by auxotrophic mutants were added at final concentrations of $30-50 \mu \mathrm{g}$ $\mathrm{ml}^{-1}$ for amino acids and $1 \mathrm{mM}$ for hypoxanthine. Acid production by mutants was revealed on plates containing bromocresol purple and $\mathrm{CaCO}_{3}$, prepared according to Carls \& Hanson (1971).

Cells were precultured on Tryptose Blood Agar base (TBAB; Difco) plates for $8-15 \mathrm{~h}$. They were suspended in synthetic medium; the $A_{600}$ was measured at an appropriate dilution $\left(A_{600}\right.$ below 0.8$)$, and the cells were inoculated into the growth medium to give a calculated $A_{600}$ of about 0.001 . The cultures, occupying $1 / 10$ or less of an Erlenmeyer flask, were shaken in a reciprocating shaker at 120 r.p.m., $37^{\circ} \mathrm{C}$. Growth was followed by measuring the $A_{600}$ in a Gilford spectrophotometer. The viable cell titre $(V)$ and heat-resistant spore titre $(S)$ were determined by diluting the culture in $0.1 \mathrm{M}$-potassium phosphate buffer $\mathrm{pH} 6 \cdot 5$, containing $1 \mathrm{mM}-\mathrm{MgCl}_{2}(\mathrm{PM}$ buffer), and plating both immediately, and after 20 min incubation at $75^{\circ} \mathrm{C}$, on TBAB plates. In some experiments, in which we felt it was important to observe even only partially developed spores, we measured the octanol-resistant spore titre. In this method, $5 \mu \mathrm{l}$ octanol was added to $1 \mathrm{ml}$ culture, and the tube left for $5 \mathrm{~min}$ at $37^{\circ} \mathrm{C}$. After dilution with PM buffer the cells were plated on TBAB plates (Cooney et al., 1977).

Amino acid determinations. Cell extracts were prepared for amino acid analysis by the amino acid analyser as described by Whiteman et al. (1980). To demonstrate that the large amount of glutamate observed was actually Land not D-glutamate, L-glutamate was also assayed enzymically using glutamate dehydrogenase and $\mathrm{NADH}_{2}$ in glycine/hydrazine buffer according to Bernt \& Bergmeyer (1971).

In some experiments employing a medium containing glutamate, the amount of glutamate remaining in the culture medium was determined after centrifugation of a $1.3 \mathrm{ml}$ sample for $2 \mathrm{~min}$ in an Eppendorf microfuge. A 1 $\mathrm{ml}$ volume of the supernatant was adjusted to $\mathrm{pH} 9 \cdot 0$ with $\mathrm{NaOH}$ and was then freeze-dried to remove most of the ammonia. The dried material was solubilized in $1.0 \mathrm{ml} \mathrm{H}_{2} \mathrm{O}$.

Gene transfer by transformation or transduction. To prepare DNA for transformation, cells growing exponentially in $100 \mathrm{ml}$ glucose medium containing $20 \mathrm{mM}$-glutamate plus any auxotrophic requirements were harvested at an $A_{600}$ of 1.0 and washed with $40 \mathrm{ml} \mathrm{Tris} / \mathrm{HCl}(50 \mathrm{mM}, \mathrm{pH} 7.8)$ containing $50 \mathrm{~mm}$-EDTA (Tris/EDTA). The cells were suspended in $5 \mathrm{ml}$ Tris/EDTA and incubated with $100 \mu \mathrm{g}$ lysozyme $\mathrm{ml}^{-1}$ at $37^{\circ} \mathrm{C}$ for $20 \mathrm{~min}$. Protease $\mathrm{K}$ (50 $\mu \mathrm{g} \mathrm{ml}^{-1}$ final concentration) and SDS $(0.5 \%, \mathrm{w} / \mathrm{v}$ final concentration) were added, and the mixture was incubated for $10 \mathrm{~min}$ at $37^{\circ} \mathrm{C}$. Phenol $(5 \mathrm{ml})$, saturated with Tris/EDTA, was added and thoroughly mixed with the extract using a Pasteur pipette. This mixture was mixed with $1 \mathrm{ml}$ chloroform/isoamyl alcohol $(25 ; 1)$, to dissolve lipids and produce a clear interface, and then centrifuged at $10000 \mathrm{~g}$ for $20 \mathrm{~min}$. The top layer was removed and mixed with $1 / 9 \mathrm{vol} .4 \mathrm{M}-\mathrm{NaCl}$. Ethanol (2 vol.) was layered on top, and DNA threads were collected on a glass rod and then washed with $70 \%$ ethanol. After removal of most of the ethanol, the DNA was dissolved in $1.5 \mathrm{ml} 100 \mathrm{mM}$ Tris/ $\mathrm{HCl}$ containing $10 \mathrm{~mm}-\mathrm{EDTA}, \mathrm{pH} \mathrm{8.0.} \mathrm{When} \mathrm{the} \mathrm{DNA} \mathrm{was} \mathrm{dissolved,} \mathrm{an} \mathrm{equal} \mathrm{volume} \mathrm{of} 4 \mathrm{M}-\mathrm{NaCl}$ was 
Table 1. Origin and characteristics of the Bacillus subtilis strains used

Strain

\section{1}

60015

60198

60813

61423

61469

61473

61639

61684

61705

61708

61709

61711

61716

61852

61964

62017

62092

62109

62156

62159

62160

62163

62172

62173

62177

62222

62223

62225

$$
\text { Genotype* }
$$

$\operatorname{trpC2}$

metC7 trp C2

OrdAl

citD metC7 trpC2

citG $\operatorname{trp} C 2$

lys-3 metB104 trpC2

his A1 leuA8 lys-1 metB purB thrA5 trpC2

metC7 purHl spdAl trpC2

GuaC3 metC7 purH1 spdAl trpC2

arol906 purB33 dalA1 trpC2

gltA292 trpC2

aroD120 lys-1 trpC2

hisAl thr-5 trpC2

metBlO purH1 trpC2

lys relAl trpC2

metC7 spdA1 trpC2

ilvBdell kauAl purHI relAI

metC7 OrdAI trpC2

hisAl spdA1 trpC2

citG metC7 spdAl trpC2

GuaC3 metC7 spdAl trpC2

citD GuaC3 metC7 spdAl trpC2

citG ilvBdell kauAl relAl

his $A 1$ leuA8 lys-1 metB purB spdAl trpC2

his $A 1$ leuA8 lys- 1 met $B$ pur $B$ trp $C 2$

$\operatorname{trp} C 2$

his Al lys-1 metB purB spdAI trpC2

hisAl lys-1 metB purB relAl spdAl trpC2

his $A 1$ lys-1 metB purB relAl spdA1 trpC2

\section{Origin $\dagger$}

Spizizen 168

E. Nester, SB 26

Whiteman et al. (1980), $60009+\mathrm{UV}$

$60015+$ NTG

Carls \& Hansen (1971), 1 A8

F. Young, BR151

T. Iijima, HLL $3 \mathrm{~g}$

Freese et al. $(1979 a), 60015$ + EMS

$61639+$ EMS

Dedonder et al. (1977), QB928

Dedonder et al. (1977), QB922

Dedonder et al. (1977), QB935

Dedonder et al. (1977), QB917

Tf of 61469 by 61639

J. Gallant, BR 17

Tf of 61639 by 60198

Tf of 61885 by 61676

Tf of 61639 by 60198

Tf of 61711 by 61639

Tf of 61639 by 61423

Tf of 61684 by 60813

Tf of 61684 by 60813

Tf of 62017 by 61423

Td of 61473 by 61639

Td of 61473 by 61639

Reversion of 61423

Td of 62172 by 61852

Td of 62172 by 61852

Td of 62172 by 61852

* Standard B. subtilis gene symbols are used (Henner \& Hoch, 1980). For unmapped mutations the first letter of the gene symbol is capitalized. pur indicates a block in the common purine pathway: such a mutant can grow with adenine, guanine, or hypoxanthine as a purine source. GuaC3 is an unmapped mutation that produces a deficiency in guanosine monophosphate reductase (T. Endo \& E. Freese, unpublished). OrdAl is an unmapped mutation that produces a deficiency of the inducible L-ornithine : 2-oxoacid aminotransferase (Whiteman et al., 1980). spdAI is the mutation investigated here, which causes continual sporulation in glucose medium.

† Abbreviations: EMS, NTG, and UV indicate mutagenesis by ethyl methanesulphonate, $N$-methyl- $N^{\prime}$-nitro$N$-nitrosoguanidine, and ultraviolet radiation, respectively. Tf denotes transformation by DNA and Td denotes transduction of the first strain by a PBS 1 phage lysate obtained from the second strain.

added and the solution was kept at $4{ }^{\circ} \mathrm{C}$. To transform a given marker into a recipient strain (by congression), donor DNA ( $50 \mathrm{\mu g} \mathrm{ml}^{-1}$ final concentration) was added to a culture of bacteria auxotrophic for the property to be selected against and the mixture incubated according to lijima et al. (1977). After $2 \mathrm{~h}$, the cells were plated on selective medium, and colonies possessing the desired marker were isolated.

For transduction by phage PBS1, a phage lysate was prepared from the donor strain grown in $1.75 \%(\mathrm{w} / \mathrm{v})$ Antibiotic Medium 3 (Difco); the lysate was treated with $10 \mu \mathrm{g}$ DNAase $\mathrm{ml}^{-1}$ for $30 \mathrm{~min}$ at $37^{\circ} \mathrm{C}$. Recipient strains were grown in Antibiotic Medium to an $A_{600}$ of 1.0 . A $3 \mathrm{ml}$ volume of the culture and $3 \mathrm{ml}$ PBS1 lysate were mixed and incubated for $20 \mathrm{~min}$ at $37^{\circ} \mathrm{C}$. The cells were washed with PM buffer and plated on selective medium which contained : glucose medium, $20 \mathrm{mM}$-glutamate, $0.001 \%(\mathrm{w} / \mathrm{v})$ yeast extract and auxotrophic requirements as appropriate. Cells not treated with PBS1 phage were also plated on the selective medium to measure the reversion frequency of the selected marker. To identify the $s p d A$ marker, isolated transformants were grown in glucose medium to the end of exponential growth or early into the stationary phase; if the frequency of phase-bright spores, observed under the phase-contrast microscope, was higher than $10 \%$, the isolate was scored as $s p d A$.

Selection and identification of transformants or transductants. The OrdA property (see Table 1) was identified by slow growth of cells on plates containing glucose medium in which $\left(\mathrm{NH}_{4}\right)_{2} \mathrm{SO}_{4}$ was replaced by $10 \mathrm{mM}-\mathrm{Na}_{2} \mathrm{SO}_{4}$ and $2 \mathrm{mM}$-ornithine as nitrogen source; OrdA mutants grew well if the ammonium-free medium contained $2 \mathrm{mM}$ glutamate. The deficiency of 2-oxoglutarate dehydrogenase (citD) was identified by acid production on bromocresol purple plates.

Deficiency of fumarase ( $c i t G)$ was determined by the inability of strains to grow on aspartate as sole carbon source (synthetic medium containing $20 \mathrm{~mm}$-potassium aspartate and appropriate auxotrophic requirements). The 
reversion to $\mathrm{citG}^{+}$was revealed by the loss of the extensive acid production on bromocresol purple plates. Fumarase activity was also assayed in cell extracts according to Hanson \& Cox (1967).

The $\mathrm{rel}^{+}$or rel property was ascertained by measuring the incorporation of $\left[{ }^{3} \mathbf{H}\right]$ uracil into TCA-precipitable material. Cells were cultured in glucose medium containing glutamate $(20 \mathrm{mM})$, histidine $\left(30 \mu \mathrm{g} \mathrm{ml}^{-1}\right)$, lysine $(50 \mu \mathrm{g}$ $\mathrm{ml}^{-1}$ ) and hypoxanthine $(0.5 \mathrm{mM})$. When the $A_{600}$ reached 1, the culture was diluted with fresh medium containing [ $\left.{ }^{3} \mathrm{H}\right]$ uracil $\left[0.1 \mu \mathrm{Ci} \mathrm{ml}^{-1}\left(3.7 \mathrm{kBq} \mathrm{ml}^{-1}\right)\right.$ and $15 \mu \mathrm{M}$ final concentration] to an $A_{600}$ of 0.15 . After shaking for $5 \mathrm{~min}$ the culture was divided into two equal portions, one of which received granaticin (final concentration $0 \cdot 2 \mu \mathrm{g} \mathrm{ml}^{-1}$ ). Every $5 \mathrm{~min}$ for $40 \mathrm{~min}, 0.5 \mathrm{ml}$ of each culture was mixed with $0.5 \mathrm{ml}$ ice-cold $10 \%(\mathrm{w} / \mathrm{v}) \mathrm{TCA}$. After $2 \mathrm{~h}$ in the cold, the precipitate was filtered on to a membrane filter (pore size $0.45 \mu \mathrm{m}$ ) and washed twice with $4 \mathrm{ml}$ ice-cold $5 \%$ $(w / v)$ TCA; the radioactivity of the collected material was determined in a scintillation counter (LKB 1210) using Aquasol (New England Nuclear) as the scintillation fluid.

Enzyme assays. To prepare cell extracts, cells were cultured in glucose medium containing appropriate auxotrophic requirements. When the $A_{600}$ reached $1,35 \mathrm{ml}$ of culture was centrifuged at $10000 \mathrm{~g}$ for $10 \mathrm{~min}$ at $4{ }^{\circ} \mathrm{C}$. The cells were washed with $0.05 \mathrm{M}-\mathrm{Tris} / \mathrm{HCl}(\mathrm{pH} \mathrm{7.2)}$ and suspended in $0.9 \mathrm{ml}$ of this buffer. Lysozyme (100 $\mu \mathrm{l} ; 1 \mathrm{mg} \mathrm{m}^{-1}$ ) was added, and the mixture left at $37^{\circ} \mathrm{C}$ for $20 \mathrm{~min}$. The lysate was centrifuged at $15000 \mathrm{~g}$ for $20 \mathrm{~min}$ to remove cell debris. The supernatant was used for enzyme assays. Protein was measured according to Kalb \& Bernlohr (1977).

Pyruvate carboxylase was assayed spectrophotometrically at $20^{\circ} \mathrm{C}$ (Diesterhaft \& Freese, 1973). The reaction mixture contained $50 \mathrm{~mm}-\mathrm{Tris} / \mathrm{HCl}(\mathrm{pH} \mathrm{7} \cdot 5), 5 \mathrm{~mm}-\mathrm{MgCl}_{2}, 1 \mathrm{~mm}-\mathrm{NADH}, 35 \mathrm{~mm}-\mathrm{NaHCO}_{3}, 2 \mathrm{~mm}-\mathrm{ATP}, 0 \cdot 2 \mathrm{~mm}-$ acetyl-CoA and $50 \mu \mathrm{g}$ malate dehydrogenase $\mathrm{ml}^{-1}$. The reaction was started by the addition of $2 \mathrm{~mm}$-pyruvate and followed by the decrease in $A_{340}$. The specific activities are expressed in nmol NADH consumed (mg protein) ${ }^{-1}$ $\min ^{-1}$.

Pyruvate dehydrogenase was assayed at $20^{\circ} \mathrm{C}$ as described for 2-oxoglutarate dehydrogenase by Reed \& Mukherjee (1969). The reaction mixture contained $50 \mathrm{~mm}$-potassium phosphate buffer (pH 6.5), $1 \mathrm{~mm}-\mathrm{MgCl}_{2}, 1$ mM-NAD, $0.5 \mathrm{~mm}$-EDTA, $2 \mathrm{~mm}$-glutathione, $0.1 \mathrm{~mm}$-coenzyme A, and $0.2 \mathrm{~mm}$-thiamin pyrophosphate. The reaction was initiated by the addition of $1 \mathrm{~mm}$-sodium pyruvate, and the rate of increase in $A_{340}$ was measured. The specific activities are expressed in nmol NAD reduced (mg protein $)^{-1} \mathrm{~min}^{-1}$.

\section{RESULTS}

Growth and sporulation of strains containing the spdA1 mutation

Among the purine mutants whose sporulation had been examined in synthetic medium containing excess ( $55 \mathrm{~m} \mathrm{M}$ ) glucose (glucose medium) with purine supply limiting (Freese et al., $1979 a$ ), we found some strains which sporulated continually even in the presence of excess (1 mM) hypoxanthine. We do not know whether the mutations (termed spd) causing such continual sporulation often arise spontaneously or whether they occurred due to some inadvertent selection. The typical growth and sporulation behaviour of such a strain (61639) purH spdAl is shown in Fig. 1(a) (only the relevant gene symbols are mentioned in the text). Following inoculation of glucose medium containing 1 mM-hypoxanthine at a low $A_{600}(0.001)$, the heatresistant spore titre increased throughout growth and thereafter. Apparently, in every cell generation a certain fraction of cells was initiated to enter the sporulation process. Neither glucose nor hypoxanthine was used up at the end of the experiment. In contrast, the parent (strain 60015) produced far fewer spores and most of these only after growth had stopped (Fig. $1 b$ ).

Addition of glutamate to the glucose medium suppressed sporulation of the spdAl mutant until glutamate had been used up (the glutamate decrease is shown in the inset to Fig. $1 a$ ). With $20 \mathrm{mM}$-glutamate, sporulation remained suppressed throughout the experiment. This amount of glutamate also suppressed the small increase in the spore titre of our standard strain (60015; Fig. $1 b$ ).

The approximate map location of the spdAl marker was determined by transducing the 'kit' strains provided by Dedonder et al. (1977) for mapping purposes with phage PBSl grown in strain 61639 . The spdAI marker was linked most closely to the $t h r$ marker (63 out of $76 t h r^{+}$ transductants were $s p d A)$ and more loosely to his $A(17 / 99)$ and citG $(26 / 50)$. For a map of the auxotrophic markers see Henner \& Hoch (1980).

The continual sporulation observed in strain 61639 did not depend on the purine requirement of the pur $H$ mutant. When the pur $H$ marker of strain 61639 was transformed into another strain (61469), the resulting strain (61716) produced only $7 \cdot 3 \times 10^{4}$ spores $\mathrm{ml}^{-1}$ after $12 \mathrm{~h}$ in glucose 

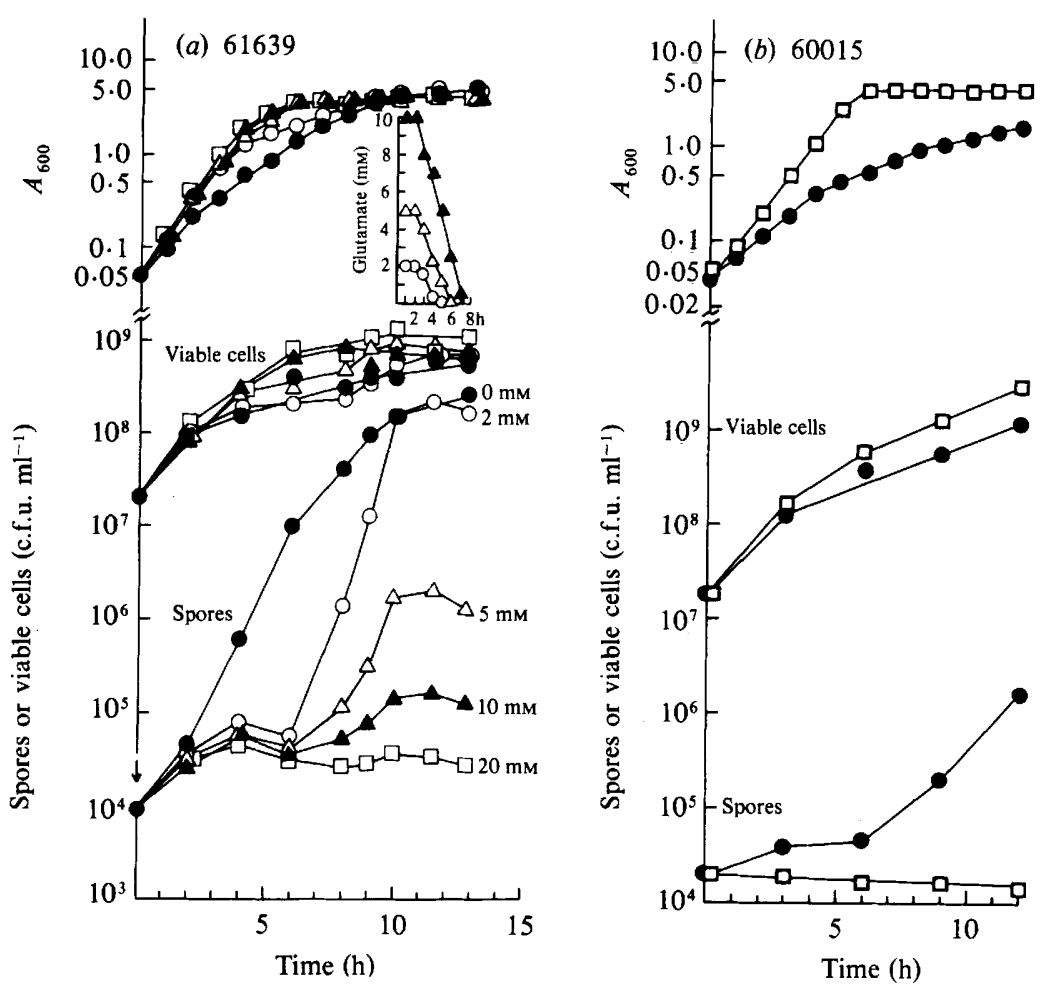

Fig. 1. Growth and sporulation of the spdAI mutant (61639) and its parent (60015) without and with glutamate. $(a)$ Cells of strain 61639 were inoculated into $100 \mathrm{ml}$ glucose medium supplemented with 1 mM-hypoxanthine to give an $A_{600}$ of 0.001 . When the $A_{600}$ reached 0.05 , the culture was divided into five portions which received: no addition $(\odot)$, or glutamate at $2 \mathrm{~mm}(\mathrm{O}), 5 \mathrm{~mm}(\triangle), 10 \mathrm{mM}(\Delta)$ or $20 \mathrm{~mm}$ ( $\square$ ) (final concentrations). Thbe $A_{600}$ (top) was monitored and viable cell titre (middle) and heat-resistant spore titre (bottom) were determined at the indicated times. The numbers on the curves indicate the initial glutamate concentrations. The glutamate concentrations remaining in the cultures at different times are shown in the inset. $(b)$ The standard strain (60015) was cultured in glucose medium as above. When the $A_{600}$ reached 0.04 , the culture was divided into two portions which received: no addition ( $\bigcirc$ ) or $20 \mathrm{mm-glutamate}(\square)$.

medium containing $1 \mathrm{~mm}$-hypoxanthine (grown as in Fig. 1). A similar spore titre $\left(2 \cdot 1 \times 10^{4}\right.$ $\mathrm{ml}^{-1}$ ) was produced when the medium contained $20 \mathrm{~mm}$-glutamate. Similarly, when the purH marker of strain 61639 was removed by transformation with DNA of a pur ${ }^{+}$strain (60198), all 10 isolated and purified pur $^{+}$transformants sporulated in glucose medium equally as well as strain 61639; addition of $1 \mathrm{~mm}$-hypoxanthine, $1 \mathrm{~mm}$-adenine or $1 \mathrm{~mm}$-guanosine did not significantly affect the sporulation frequency. One of these pur $^{+}$strains, 61964 (spdA1), was used for most of the following experiments.

We also assessed the ability of the spdA1 marker to cause continual sporulation by maintaining a culture of strain 61964 at an essentially constant $A_{600}$ for $17 \mathrm{~h}$. For this purpose the culture was diluted twofold in glucose medium whenever the $A_{600}$ reached 0.4 . The titre of heat-resistant spores per viable cell initially increased rapidly and then remained almost constant at a value of about $5 \times 10^{-2}$ (Fig. 2). The viable cell titre reached a maximum and then decreased very slowly, probably because an increasing fraction of the cells entered spore development and thus no longer divided. Under the same growth conditions, the spore titre of a culture of strain 60015 remained lower and that of a culture of strain 60001 remained much lower, although both values increased slowly (Fig. 2).

The continual sporulation of spdAl strains in glucose medium could be prevented not only by glutamate but also by other compounds providing carbon to the citrate or the arginine cycle. 


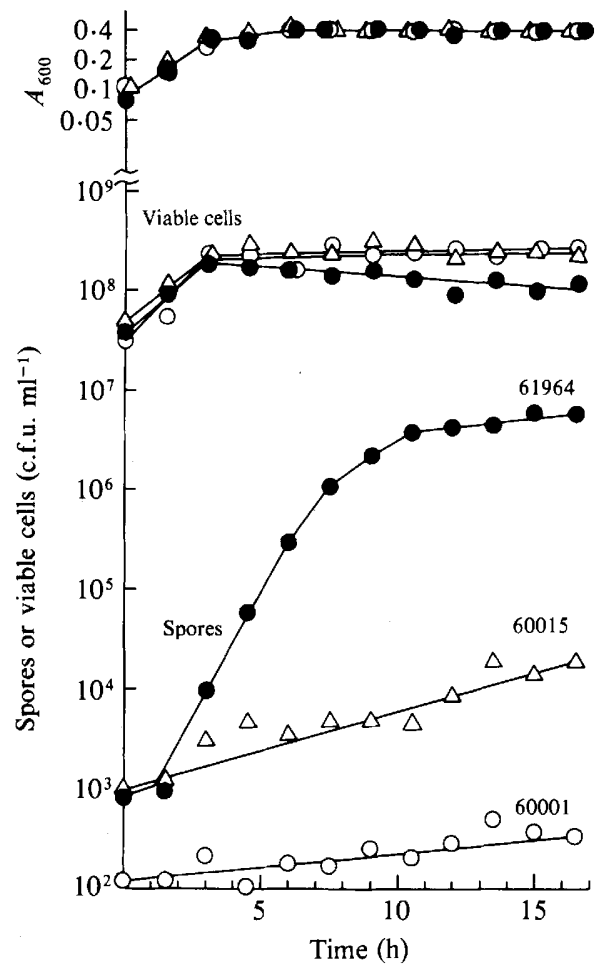

Fig. 2. Sporulation of the spdAl mutant (61964), its parent (60015) and Spizizen's 168 strain (60001) in cultures maintained at a constant $A_{600}$. Strains $60001(\bigcirc), 60015(\triangle)$ and $61964(\bigcirc)$ were grown in glucose medium to an $A_{600}$ of 0.4 . A $5 \mathrm{ml}$ sample of each culture was mixed with $5 \mathrm{ml}$ prewarmed glucose medium, and mixtures were shaken until the $A_{600}$ reached 0.4 again. This dilution and growth was repeated every $90 \mathrm{~min}$ for $14.5 \mathrm{~h}$; the $A_{600}$ of the cultures was thereby kept between $0 \cdot 2$ and $0 \cdot 4$. The $A_{600}$ (top) was always measured before dilution. The viable cell titre (middle) and spore titre (bottom) were determined every $90 \mathrm{~min}$.

This is shown for strain 61964 (spdAl) in Table 2; other amino acids (such as alanine, isoleucine, methionine, valine, etc.), purines or pyrimidines had no effect (legend to Table 2).

Conceivably, the compounds suppressing sporulation did not prevent its initiation but interfered with some later stage of the sporulation process. To examine this possibility, strain 61964 was grown in glucose medium containing $20 \mathrm{mM}$-glutamate and, at an $A_{600}$ of 0.05 , either decoyinine $(400 \mu \mathrm{M})$ or mycophenolic acid $(200 \mu \mathrm{M})$ was added to induce sporulation (Mitani et al., 1977; Freese et al., 1979b). With both inducers a massive increase in the spore titre was observed 6-8 h after their addition. At $t_{10}$ the spore titre was $2 \cdot 1 \times 10^{5} \mathrm{ml}^{-1}$ without inducer, but $1.9 \times 10^{8} \mathrm{ml}^{-1}$ with decoyinine and $2.3 \times 10^{8} \mathrm{ml}^{-1}$ with mycophenolic acid. Similar induction of sporulation was obtained in cultures in which continual sporulation was prevented by arginine, aspartate, citrate, glutamine, malate, or ornithine (each at $10 \mathrm{~mm}$ ). These results indicate that the compounds suppressing the continual sporulation interfered with the initiation of sporulation and not with later spore development.

\section{Genetic and biochemical approaches to determine the basis of the spdA1 mutation}

The above results had shown that a compound metabolically associated with the arginine or the citrate cycle was required to suppress the continual sporulation resulting from the $s p d A 1$ mutation. We separated the two cycles by a mutation (OrdAl) which produced a deficiency in ornithine :2-oxoacid aminotransferase and thereby prevented the conversion of ornithine to glutamic $\gamma$-semialdehyde and glutamate (Whiteman et al., 1980). The OrdAl mutation was transformed (by congression) into strain 61639, producing the OrdA1 spdA1 strain (62092). 
Table 2. Effect of various compounds on the sporulation of the spdA1 strain 61964

Strain 61964 was cultured in $350 \mathrm{ml}$ glucose medium from $A_{600}=0.005$ to $A_{600}=0.05$. Samples $(10 \mathrm{ml})$ were then transferred into $125 \mathrm{ml}$ flasks containing one of the stated compounds. After $10 \mathrm{~h}$ further incubation, the viable cell titre and spore titre were determined; the former was between $1.7 \times 10^{8} \mathrm{ml}^{-1}$ and $1.1 \times 10^{9} \mathrm{ml}^{-1}$. Addition of D-glucose, $\left(\mathrm{NH}_{4}\right)_{2} \mathrm{SO}_{4}, \mathrm{KH}_{2} \mathrm{PO}_{4}$, L-valine, L-isoleucine, L-alanine, $\mathrm{L}$ homoserine, L-methionine or acetate (each at $10 \mathrm{mM}$ ), glycine, L-phenylalanine or L-tryptophan (each at $5 \mathrm{~mm}$ ), putrescine ( $2 \mathrm{~mm}$ ), or adenine, guanosine, hypoxanthine, uracil or thymine (each at $1 \mathrm{~mm}$ ) did not affect sporulation (spore titres between $1.5 \times 10^{8} \mathrm{ml}^{-1}$ and $4.8 \times 10^{7} \mathrm{ml}^{-1}$ ).

$$
\begin{array}{ccc}
\text { Compound } & \begin{array}{c}
\text { Contration } \\
(\mathrm{mM})
\end{array} & \begin{array}{c}
10^{-5} \times \text { Spore } \\
\text { titre } \mathrm{ml}^{-1}
\end{array}
\end{array}
$$

$\begin{array}{lrr}\text { No addition } & - & 1300 \cdot 0 \\ \text { L-Glutamate } & 10 & 0 \cdot 8 \\ \text { L-Glutamine } & 10 & 7 \cdot 5 \\ \text { L-Aspartate } & 10 & 2 \cdot 4 \\ \text { L-Ornithine } & 10 & 2 \cdot 3 \\ \text { L-Citrulline } & 10 & 17 \cdot 0 \\ \text { L-Arginine } & 10 & 2 \cdot 5 \\ \text { L-Histidine } & 10 & 14 \cdot 0 \\ \text { DL-2,6-Diaminopimelic acid } & 10 & 95 \cdot 0 \\ \text { L-Lysine } & 10 & 60 \cdot 0 \\ \text { L-Proline } & 5 & 42 \cdot 0 \\ \text { L-Malate } & 10 & 2 \cdot 7 \\ \text { Citrate } & 10 & 3 \cdot 3 \\ \text { Succinate } & 10 & 360 \cdot 0 \\ \text { Pyruvate } & 10 & 400 \cdot 0 \\ \text { 2-Oxoglutarate } & 10 & 3 \cdot 2\end{array}$

When this strain was transferred from glucose medium to the same medium containing $10 \mathrm{~mm}$ ornithine instead of $\left(\mathrm{NH}_{4}\right)_{2} \mathrm{SO}_{4}$ as nitrogen source, it grew only slowly (doubling time of 330 $\mathrm{min}$ ), whereas it grew well with glutamate as nitrogen source (doubling time $70 \mathrm{~min}$ ). Strain 61964 (spdAI), obtained in the same transformation procedure, grew well on both glutamate and ornithine (doubling time $70 \mathrm{~min}$ ) because it had not received the $O r d A 1$ mutation. In common with the results shown in Fig. 1, glutamate and citrate increased the rate of growth and suppressed the continual sporulation of both strains, whereas ornithine or arginine had this effect only for the $\mathrm{Ord}^{+}$strain 61964. In the $\mathrm{OrdAl}$ mutant (62092), ornithine suppressed the continual sporulation only slightly and arginine did not suppress it at all (Table 3 ). Thus the compound controlling the continual sporulation must be associated with the citrate cycle rather than the arginine cycle.

To locate the sporulation-controlling compound more accurately, a deficiency in 2oxoglutarate dehydrogenase (citD gene of strain 60813) was introduced by congression into a strain containing spdA (61684). In the resulting citD spdAl transformant (62160), continual

\section{Table 3. Comparison of sporulation of the spdA1 strain (61964) and the OrdA1 spdA1 strain} (62092) in the presence of different compounds

Cells were cultured in glucose medium as detailed in Table 2 . When the $A_{600}$ was 0.05 , the stated compounds were added ( $10 \mathrm{~mm}$ final concentration). The viable cell titre $(V)$ and heat-resistant spore titre $(S)$ were determined $10 \mathrm{~h}$ later.

\begin{tabular}{|c|c|c|c|c|}
\hline \multirow[b]{2}{*}{$\begin{array}{l}\text { Addition ( } 10 \mathrm{~mm}) \\
\text { to glucose medium }\end{array}$} & \multicolumn{2}{|c|}{ Strain $61964(s p d A l)$} & \multicolumn{2}{|c|}{ Strain $62092($ OrdAl spdAl) } \\
\hline & $\begin{array}{c}10^{-5} \times \text { Spore } \\
\text { titre } \mathrm{ml}^{-1}\end{array}$ & $S / V$ & $\begin{array}{c}10^{-5} \times \text { Spore } \\
\text { titre } \mathrm{ml}^{-1}\end{array}$ & $S / V$ \\
\hline None & 1400 & $3.0 \times 10^{-1}$ & 2400 & $3.2 \times 10^{-1}$ \\
\hline Citrate & $7 \cdot 6$ & $5.2 \times 10^{-4}$ & $7 \cdot 6$ & $5.4 \times 10^{-4}$ \\
\hline Glutamate & $1 \cdot 2$ & $1.5 \times 10^{-4}$ & $3 \cdot 8$ & $3.0 \times 10^{-4}$ \\
\hline L-Ornithine & $0 \cdot 4$ & $2.5 \times 10^{-5}$ & 130 & $1.2 \times 10^{-2}$ \\
\hline L-Arginine & 93 & $7 \cdot 1 \times 10^{-3}$ & 1700 & $2.3 \times 10^{-1}$ \\
\hline
\end{tabular}


Table 4. Comparison of growth and sporulation of the spdA1 strain (62159) and the citD spdA1 strain (62160) in the presence of different compounds

Cells were cultured in glucose medium as detailed in Table 2 . When the $A_{600}$ reached 0.05 , one of the stated compounds (sodium salt) was added. The $A_{600}$ was monitored and $10 \mathrm{~h}$ after the additions, the viable cell titres (between $4.5 \times 10^{7}$ and $1.2 \times 10^{9} \mathrm{ml}^{-1}$ ) and octanol-resistant spore titres were determined.

\begin{tabular}{|c|c|c|c|c|}
\hline \multirow[b]{2}{*}{$\begin{array}{l}\text { Addition ( } 10 \mathrm{~mm}) \\
\text { to glucose medium }\end{array}$} & \multicolumn{2}{|c|}{ Strain $62159(\operatorname{spdAl})$} & \multicolumn{2}{|c|}{ Strain 62160 (citD spdAl) } \\
\hline & $\begin{array}{c}10^{-5} \times \text { Spore } \\
\text { titre } \mathrm{ml}^{-1}\end{array}$ & $\begin{array}{l}\text { Doubling } \\
\text { time (min) }\end{array}$ & $\begin{array}{c}10^{-5} \times \text { Spore } \\
\text { titre } \mathrm{ml}^{-1}\end{array}$ & $\begin{array}{l}\text { Doubling } \\
\text { time (min) }\end{array}$ \\
\hline None & 2700 & 65 & 1800 & 90 \\
\hline Malate & 70 & 48 & 43 & 50 \\
\hline Citrate & 15 & 45 & 750 & 95 \\
\hline 2-Oxoglutarate & 7 & 45 & 730 & 90 \\
\hline Aspartate & 7 & 45 & 33 & 45 \\
\hline Glutamate & 7 & 45 & 860 & 75 \\
\hline
\end{tabular}

sporulation was still suppressed by aspartate or malate, whereas citrate, glutamate, or 2oxoglutarate produced only a weak effect (Table 4). Another transformant (62159), isolated in parallel but not containing the $c i t D$ mutation, still showed the suppression of sporulation by all of the above compounds (Table 4). Apparently, the compound controlling continual sporulation was one of the metabolites in the citrate cycle between succinyl-CoA and oxaloacetate, or was derived from such a metabolite. Such a derived compound is aspartate, which in turn serves as a precursor for a number of amino acids. To determine whether the production of any particular amino acid was significantly altered in the spdA strain, cells of strains 61964 and 60015 growing in glucose medium at an $A_{600}$ of 1 were extracted with formic acid and the amino acid composition of the extract was determined in the amino acid analyser. Compared with strain 60015 , the amino acid concentrations in strain 61964 were somewhat lower for aspartate $(37 \%)$ and methionine $(41 \%)$, and higher for alanine $(72 \%)$, glutamine $(80 \%)$, proline $(100 \%)$ and valine $(330 \%)$. The other amino acid concentrations were similar in the two strains. The concentration of glutamate was always much higher than that of any other amino acid; it was slightly higher ( $94 \mathrm{nmol}$ per $A_{600}$ unit) in strain 61964 than in strain 60015 (85 nmol per $A_{600}$ unit). To determine whether the large glutamate peak represented L- or D-glutamate, we also measured L-glutamate enzymically; 95 and $87 \mathrm{nmol}$ per $A_{600}$ unit was found in strains 61964 and 60015 respectively. Thus most (or all) of the intracellular glutamate was in the L-form.

To examine whether valine, the amino acid whose concentration was particularly high in the $\operatorname{spd} A$ strain 61964, might be responsible for the increased sporulation frequency of this strain, the standard strain (60015) was grown in glucose medium with different amounts (up to $10 \mathrm{~mm}$ ) L-valine. The spore titres, measured $12 \mathrm{~h}$ after the $A_{600}$ reached 0.5 , were all between $1.4 \times 10^{5}$ and $1.7 \times 10^{5} \mathrm{ml}^{-1}$, regardless of the valine concentration. Therefore, the increased valine concentration did not appear to be responsible for the increased sporulation frequency of the spdA mutant.

\section{Effect of a fumarase mutation and assay of pyruvate carboxylase}

Additional information was obtained by using the citG mutation which disables the production of fumarase. The $c i t G$ strain (61423) grew at a low rate in glucose medium (Fig. 3) and excreted large quantities of fumarate as shown by acid production on bromocresol purple plates. The growth rate in glucose medium increased with the addition of $20 \mathrm{~mm}$-2-oxoglutarate, citrate, glutamate, malate, or aspartate, in this sequence (only the results for citrate and malate are shown in Fig. 3). Apparently, the citG mutant converted so much of its limiting oxaloacetate (produced from glucose) into the excreted fumarate that it could not produce enough aspartate. Added glutamate (and its precursor citrate) probably counteracted this drain by feed-back inhibition and because glutamate (or 2-oxoglutarate) represses citrate synthase and aconitase (Hanson \& Cox, 1967). This was confirmed by amino acid analysis of cell extracts. When strains 


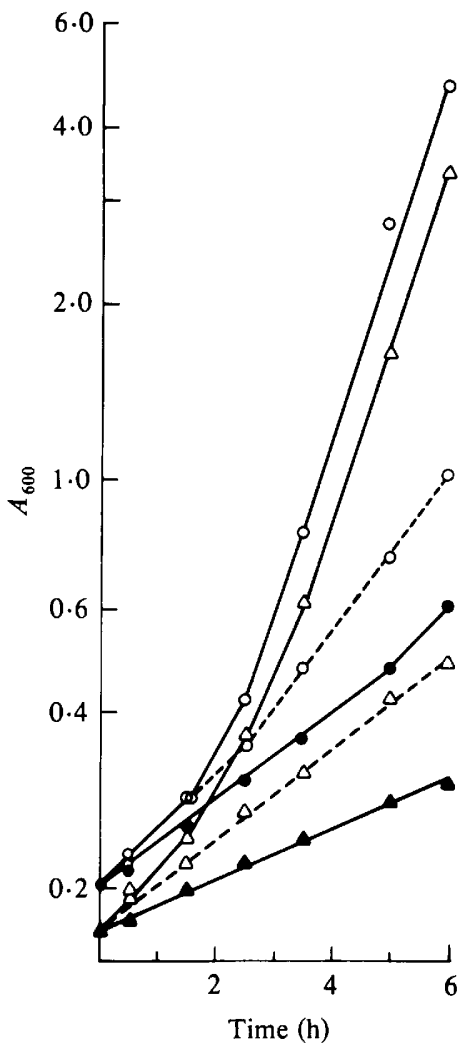

Fig. 3. Comparison of growth rates of $c i t G$ strain (61423) and citG spdA1 transformant (62156). The cells were cultured in glucose medium containing $20 \mathrm{mM}$-glutamate. At an $A_{600}$ of 0.2 , the cells were collected on membrane filters and resuspended in prewarmed glucose medium without glutamate. Each cell suspension was divided into three portions which received : 20 mM-potassium citrate $(\triangle---\triangle$, strain $62156 ; \bigcirc--\bigcirc$, strain 61423), 20 mM-potassium malate $\triangle \triangle \triangle$, strain $62156 ; \bigcirc-\bigcirc$, strain $61423)$, or no addition , strain 62156;

, strain 61423).

were grown to an $A_{600}$ of 1 in glucose medium containing $20 \mathrm{~mm}$-glutamate and then extracted, the cit $G$ mutant cells $(61423)$ contained 83 pmol glutamate per $A_{600}$ unit but only $0.5 \mathrm{pmol}$ aspartate per $A_{600}$ unit, whereas the standard strain (60015) contained 86 pmol glutamate per $A_{600}$ unit and $2.5 \mathrm{pmol}$ aspartate per $A_{600}$ unit. Thus, even in the presence of glutamate, aspartate was scarce.

Since the presence of both the $\operatorname{cit} G$ and $\operatorname{spd} A$ mutations in one strain might reveal more clearly with which metabolic reaction the $s p d A$ mutation interfered, we introduced the $c i t G$ mutation into the $s p d A 1$ strain (61639) by congression. The resulting $\mathrm{cit} G$ spdAl strain (62156) grew even more slowly than the cit $G$ strain (61423) in glucose medium with or without citrate (Fig. 3), but in the presence of aspartate, glutamate (result not shown) or malate, this strain grew at the same rate as the $c i t G$ strain. The results suggested that the $s p d A I$ mutation decreased the rate at which glucose could supply oxaloacetate. Therefore, we examined the growth on pyruvate.

Our standard strain (60015) grew distinctly faster than the spdAI mutant (61964) in synthetic medium with pyruvate $(100 \mathrm{mM})$ as sole carbon source. To our surprise, the original $\operatorname{trp} C$ mutant of Spizizen (60001) grew on pyruvate even faster. All three strains grew at the same rate (doubling time $80 \mathrm{~min}$ ) in synthetic medium plus $100 \mathrm{~mm}$-glucose or malate (results not shown). Because the metabolism of pyruvate was limited, we measured the specific activity of pyruvate carboxylase in these three strains and also in related strains. These activities were compared with the extent of sporulation in glucose medium. As the results in Table 5 show, strain 60001 had the highest pyruvate carboxylase activity and the lowest frequency of sporulation. Strain 
Table 5. Correlation of pyruvate carboxylase activity and sporulation in glucose medium

\begin{tabular}{|c|c|c|c|c|}
\hline \multirow[b]{2}{*}{ Strain } & \multicolumn{2}{|c|}{ Pyruvate carboxylase* } & \multicolumn{2}{|c|}{ Sporulation $\dagger$} \\
\hline & Specific activity & $\%$ & $\begin{array}{c}\text { Glutamate } \\
\text { added (mM) }\end{array}$ & $\begin{array}{c}\text { Spore } \\
\text { titre } \mathrm{ml}^{-1}\end{array}$ \\
\hline $60001(t r p)$ & $43 \cdot 2$ & 100 & $\begin{array}{r}0 \\
20\end{array}$ & $\begin{array}{l}5.7 \times 10^{2} \\
1.0 \times 10^{3}\end{array}$ \\
\hline 60015 (trp met) & $24 \cdot 9$ & 58 & $\begin{array}{r}0 \\
20\end{array}$ & $\begin{array}{l}6.7 \times 10^{6} \\
7.5 \times 10^{3}\end{array}$ \\
\hline 61964 (trp met spdAl) & $18 \cdot 4$ & 43 & $\begin{array}{r}0 \\
20\end{array}$ & $\begin{array}{l}1.3 \times 10^{8} \\
7.7 \times 10^{4}\end{array}$ \\
\hline 61711 (trp his thr) & $35 \cdot 5$ & 82 & $\begin{array}{r}0 \\
20\end{array}$ & $\begin{array}{l}6.1 \times 10^{4} \\
2.9 \times 10^{3}\end{array}$ \\
\hline 62109 (trp his spdAI) & $17 \cdot 3$ & 40 & $\begin{array}{r}0 \\
20\end{array}$ & $\begin{array}{l}8.9 \times 10^{7} \\
1.2 \times 10^{5}\end{array}$ \\
\hline
\end{tabular}

* Pyruvate carboxylase activity [nmol NADH consumed (mg protein $)^{-1} \mathrm{~min}^{-1}$ ] was assayed in cultures grown in glucose medium plus required supplements. When the $A_{600}$ reached 1.0, extracts were prepared and assays were performed as described in Methods.

$\dagger$ The strains were cultured as detailed in Table 3 in glucose medium plus $30 \mu \mathrm{g}$ histidine $\mathrm{ml}^{-1}$ for strains 61711 and 62109 , and $20 \mu \mathrm{g}$ threonine $\mathrm{ml}^{-1}$ for strain 61711 . When the $A_{600}$ reached $0 \cdot 05$, the cultures were split into two portions and glutamate $(20 \mathrm{~mm}$ final concentration) was added to one of them. The heat-resistant spore titres were determined $12 \mathrm{~h}$ after glutamate addition. The viable cell titres were between $1.2 \times 10^{8}$ and $2.3 \times 10^{9} \mathrm{ml}^{-1}$.

60015 had only about $60 \%$ of this activity and sporulated better. The two strains carrying the spdAI mutation had only $40 \%$ of the pyruvate carboxylase activity of strain 60001 and produced a high spore titre (about $10^{8} \mathrm{ml}^{-1}$ ) in glucose medium. In all strains, the spore titre remained low if the medium also contained 20 mM-glutamate (Table 5).

In contrast to pyruvate carboxylase, the specific activities of pyruvate dehydrogenase were similar in strain 60001 and the spdA1 strain 61964 (specific activities of 59.6 and 56.4 respectively).

\section{The involvement of the stringent response}

The above results suggested that strains containing the spdAl mutation were partially deficient in the production of oxaloacetate from glucose and consequently may contain slightly reduced concentrations of derived compounds such as aspartate. This suggested that the continual sporulation might be caused by a partial stringent response and would therefore be limited to $\mathrm{rel}^{+}$strains. To examine this possibility, we performed several genetic crosses which combined relA and spdAI mutations in one strain. The presence of the relaxed (relA) genes in a strain was verified by the continued uracil incorporation into acid-precipitable material following the addition of granaticin. Granaticin evokes the stringent response in $\mathrm{rel}^{+}$strains because it inhibits the acylation of leucyl-tRNA (Ogilvie et al., 1975; Lopez et al., 1981 ; Lopez et al., 1981 b). As we did not have a reliable direct biochemical assay of the presence of the $s p d A I$ mutation, we obtained our results from reciprocal crosses. The marker spdAI was transduced into a relA strain, and relA into an spdAl strain; in both cases a genetically linked marker was selected for. For the former cross, we first constructed (by congression) a relA cit $G$ strain (62163) because the cit $G$ marker could be easily scored by acid excretion, and was linked to the spdAI marker as was shown above. This strain was then transduced by PBS1 phage grown in the spdA1 strain (61639). Fifty $\mathrm{Cit}^{+}$transductants (isolated as acid non-producers on colour test plates and also confirmed as being able to grow on aspartate as sole carbon source) all produced less than $0.1 \%$ spores $18 \mathrm{~h}$ after the cells had been inoculated into glucose medium (at an $A_{600}$ of about 0.005 ) from plates containing glucose medium, $20 \mathrm{mM}$-glutamate and $50 \mu \mathrm{g} \mathrm{ml}^{-1}$ isoleucine and valine). In contrast, the $s p d A l$ strain (61964) produced more than $50 \%$ spores. According to the earlier mapping results, half of these 50 transductants should have received the spdAl marker.

For the reverse transfer of the relA marker into an spdAI strain, we first constructed a leu spdAl strain (62172) because leu is linked to relA (Smith et al., 1980). This strain was then 
Table 6. Comparison of growth and sporulation character of spdA1 and spdA1 relA strains

Cells were cultured from an initial $A_{600}$ of 0.001 in glucose medium plus $30 \mu \mathrm{g}$ histidine ml $\mathrm{m}^{-1}, 50 \mu \mathrm{g}$ lysine $\mathrm{ml}^{-1}$ and $1 \mathrm{mM}$-hypoxanthine for the first five strains, and $50 \mu \mathrm{g}$ leucine $\mathrm{ml}^{-1}$ for 62172 and 62173 . The viable cell titre $(V)$ and heat-resistant spore titre $(S)$ were measured $12 \mathrm{~h}$ after the culture passed an $A_{600}$ of 0.05 . Doubling times were

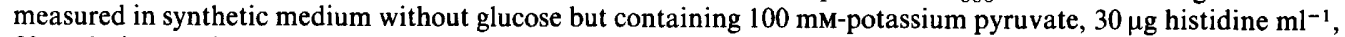
$50 \mu \mathrm{g}$ lysine $\mathrm{ml}^{-1}$ and $0.5 \mathrm{~mm}$-hypoxanthine.

\begin{tabular}{lccccccc} 
Strain & $\overbrace{\text { leu }}^{\text {relA }}$ & spdA1 & $\begin{array}{c}\text { Genetic character } \\
\text { titre } \mathrm{ml}^{-1}\end{array}$ & $S / V$ & $\begin{array}{c}\text { Doubling time } \\
\text { in pyruvate (min) }\end{array}$ \\
62172 & - & + & - & 3000 & $3.8 \times 10^{-1}$ & ND \\
62173 & - & + & + & 0.6 & $6.2 \times 10^{-5}$ & ND \\
62222 & + & + & - & 1900 & $3.3 \times 10^{-1}$ & 185 \\
62223 & + & - & - & 0.2 & $5.0 \times 10^{-3}$ & 185 \\
62225 & + & - & - & 0.2 & $2.0 \times 10^{-4}$ & 185 \\
61964 & + & + & - & 1300 & $2.0 \times 10^{-1}$ & 185 \\
60001 & + & + & + & 0.006 & $4.0 \times 10^{-7}$ & 90 \\
& & \multicolumn{7}{c}{ ND, Not determined. }
\end{tabular}

Table 7. Involvement of $\mathrm{cit} G$ in the induction of sporulation

The strains were cultured from an initial $A_{600}$ of 0.005 in glucose medium plus $20 \mathrm{mM}$-glutamate (and isoleucine and valine, each at $50 \mu \mathrm{g} \mathrm{ml}^{-1}$, for strain 62163). Octanol-resistant spore titres were determined $12 \mathrm{~h}$ after the cultures had passed an $A_{600}$ of 0.05 . The viable cell titres were between $2.3 \times 10^{8}$ and $2.6 \times 10^{9} \mathrm{ml}^{-1}$.

\begin{tabular}{|c|c|c|c|c|c|}
\hline \multirow[b]{2}{*}{ Strain } & \multicolumn{2}{|c|}{ Genetic character } & \multirow[b]{2}{*}{$\begin{array}{l}\text { Addition ( } 20 \mathrm{~mm} \text { ) } \\
\text { to glucose medium }\end{array}$} & \multirow[b]{2}{*}{$\begin{array}{l}\text { Octanol-resistant } \\
\text { spore titre } \mathrm{ml}^{-1}\end{array}$} & \multirow[b]{2}{*}{$\begin{array}{c}\text { Doubling } \\
\text { time (min) }\end{array}$} \\
\hline & $\operatorname{cit} G$ & relA & & & \\
\hline 61423 & - & + & $\left\{\begin{array}{l}\text { None } \\
\text { Aspartate } \\
\text { Malate } \\
\text { 2-Oxoglutarate }\end{array}\right.$ & $\begin{array}{l}9.1 \times 10^{7} \\
8.0 \times 10^{1} \\
5.0 \times 10^{1} \\
2.9 \times 10^{4}\end{array}$ & $\begin{array}{l}60 \\
40 \\
45 \\
60\end{array}$ \\
\hline 62163 & - & - & None & $6.0 \times 10^{4}$ & 75 \\
\hline 62177 & + & + & None & $1.4 \times 10^{2}$ & 45 \\
\hline
\end{tabular}

transduced by PBS1 phage grown in a relA strain (61852) and le $u^{+}$strains were isolated. Thirtyfive transductants, tested for sporulation in glucose medium, fell into two classes; 28 strains sporulated well whereas the remainder did not. One of the strains which sporulated well (62222) and two of the strains which did not $(62223,62225)$ were tested for their relaxed properties by measuring the rate of uracil incorporation. The results in Table 6 show that the strains containing the spdAl marker sporulated well when they were stringent $\left(\mathrm{rel}^{+}\right)$but not when they were relaxed ( $\mathrm{relA}$ ). Thus the combination of relA and spdAl prevented the expression of the $s p d A 1$ property regardless of the genetic background of the strain used.

In common with the spdAl strains, the citG strain (61423) sporulated at high frequency in glucose medium, but it sporulated even in the presence of glutamate (Table 7); a revertant of cit $G$ (62177) did not show this effect. The sporulation was prevented by the addition of aspartate or malate, both of which increased the growth rate of the cit $G$ strain. This extensive sporulation resulted from the stringent response because when the $\operatorname{cit} G$ mutation was transformed into a relA strain, the resultant citG relA strain (62163) did not sporulate in glucose medium (with or without glutamate; Table 7).

\section{DISCUSSION}

The spdAI mutation conveyed to strains capable of the stringent response ( $\mathrm{rel}^{+}$strains) the remarkable property that cells growing in glucose medium entered sporulation development at every generation at a high probability. When the $A_{600}$ of a culture of the $s p d A$ strain (61964) was 
kept within a narrow range, the spore frequency reached $5 \%$ and then increased only very slowly, which indicates that it was close to the equilibrium value (Fig. 2). While a committed cell of $B$. subtilis needs $4-5 \mathrm{~h}$ to produce a spore, the non-committed cells continue to multiply. As the doubling time (of the mixture of multiplying and committed cells and finished spores) was about $1.5 \mathrm{~h}$, it took a committed cell about three doubling times to produce a heat-resistant spore. Thus about $2^{3} \times 5 \%=40 \%$ of the cells in the culture were sporulating, contained spores or were free spores. [More accurately, the fraction of sporulating cells and spores in a growing population in which an equilibrium between sporulation and dividing cells has been reached, is $p(1+p)^{-1}$, where $p$ is the probability that a cell enters sporulation within one generation time. This relationship holds if $p$ is small compared to 1 and if germination is negligible. However, these details are unimportant for the comparison of the three strains.] For the other two strains in Fig. 2 , the spore titre continued to increase; if one assumes that the highest $S / V$ value observed was close to the equilibrium value, only $6 \times 10^{-4}$ cells of our standard strain $(60015)$ and $1.6 \times 10^{-5}$ cells of the original Spizizen 168 strain (60001) would sporulate or be finished spores at equilibrium. The 40-fold difference between strains 60015 and 60001 shows that even 'standard' strains normally used for sporulation experiments differ in their continual sporulation ability while they are growing in the same synthetic medium containing excess ammonium, glucose and phosphate but no other carbon sources supplying the citrate cycle. This explains why in other studies in which the induction of sporulation was measured, different background (noninduced) spore titres were observed when different strains and growth conditions were used (Freese et al., 1979a; Lopez et al., 1981b; Ochi et al., 1981).

The continual sporulation of $s p d A$ strains resulted from a partial stringent response since it was absent in all spdA relA mutants produced by transforming the $s p d A 1$ marker into a relA strain and vice versa. The amino acid whose partial deficiency was responsible for the frequent sporulation of spdAl mutants and also the elevated sporulation of strain 60015 , as compared with strain 60001, was apparently aspartate, as was shown by the introduction of various mutations. Enzymic studies indicated that the specific activity of pyruvate carboxylase was particularly low in spdA mutants, and also lower in 60015 than in 60001 . The activity of this enzyme, which is solely responsible for the synthesis of oxaloacetate from glucose (Diesterhaft \& Freese, 1973), controls the rate of oxaloacetate synthesis in glucose medium and thus the synthesis of the amino acids derived from citrate cycle intermediates - in particular aspartate. The concentration of aspartate was slightly (37\%) lower in the spdA mutant (61964) than in the standard strain (60015). Although this difference was not pronounced, the fact that the addition of aspartate or malate increased the growth rate of all strains indicates that the supply of these carbon sources was growth-limiting. Glutamate addition also increased the rate of growth but this was probably due to an indirect effect, because the intracellular glutamate concentration was always very high. Addition of glutamate is known to cause feed-back inhibition of its own synthesis and to repress the synthesis of citrate synthase and aconitase [the effective compound is in fact 2-oxoglutarate (Hanson \& Cox, 1967; Ohne, 1974)]. Therefore, glutamate addition probably reduces the drain of oxaloacetate in the direction of 2-oxoglutarate synthesis, making more oxaloacetate available for aspartate synthesis. The decrease of pyruvate carboxylase activity in the spdA strain (61964) also explains why the concentration of alanine and valine, whose synthesis requires pyruvate, was elevated in the spdA mutant (61964).

We do not know whether the decreased activity of pyruvate carboxylase is the only enzymic alteration caused by the $s p d A 1$ mutation. The $s p d A l$ gene is located close to the $t h r$ marker and is also linked to the cit $G$ marker. It is therefore genetically different from the pyc gene whose mutation causes complete deficiency of pyruvate carboxylase activity (Diesterhaft \& Freese, 1973). Presumably, one of the two genes ( $p y c$ or $s p d A 1)$ is the structural gene for pyruvate carboxylase, whereas the other gene controls the synthesis of this enzyme. A fumarase (citG) mutant (61423) behaved similarly to the spdA mutant. It grew slowly in glucose medium because it lacked aspartate. In addition it sporulated at a high frequency in glucose medium, a property that was prevented by the addition of aspartate or malate but not by glutamate. The sporulation of the $c i t G$ strain was also prevented by the introduction of a relA mutation. The spdAI gene is not identical to the $\operatorname{cit} G$ gene, although it is linked to it, because the spdAl mutant (61964) did not 
have a decreased specific activity of fumarase (results not shown) and, unlike the $\operatorname{cit} G$ mutant, did not excrete acid (fumaric acid).

The continual sporulation of all strains containing the $s p d A l$ or $c i t G$ mutations was effectively prevented by aspartate, whereas other amino acids, including those derived from aspartate (isoleucine, lysine, methionine, threonine) were much less effective (Table 2). Therefore, it appears likely that a partial deficiency of aspartyl-tRNA (or asparaginyl-tRNA) was responsible for the partial stringent response that caused the continual sporulation.

Although the involvement of a mild stringent response in the continual sporulation of $s p d A$ strains was clearly established by genetic means, we have not found a significantly increased pool concentration of ppGpp or pppGpp, or a significantly decreased concentration of GTP in the $s p d A 1$ strain (61964) grown in glucose medium as compared with the concentrations of these compounds in cells grown in the presence of $20 \mathrm{~mm}$-glutamate, which prevented sporulation (results not shown). Therefore, we cannot claim that the change in the concentration of any nucleotide (in particular GTP) was responsible for the increased sporulation frequency. However, the frequency at which cells of an $s p d A I$ strain entered sporulation per unit time was much lower than that at which cells enter massive sporulation after their sudden transfer to a poor medium, where a drastic (though transient) stringent response is produced (Lopez et al., $1981 a$; Lopez et al., 1981 b; Ochi et al., 1981). Presumably, every cell experiences a decrease in certain metabolites at a certain time in the cell cycle. At that time it may be particularly sensitive to an additional reduction in the synthesis of an aminoacyl-tRNA. Therefore, a slight reduction in the rate of aspartyl-tRNA synthesis in the $s p d A I$ and $c i t G$ strains may have a pronounced effect for the few cells at a critical stage of their cell cycle. To examine these biochemical details of continual sporulation, one would have to use cells that are highly synchronized with respect to the cell cycle.

\section{REFERENCES}

BERNT, E. \& BergmeYer, H. U. (1971). L-Glutamate. UV-assay with glutamate dehydrogenase and NAD. In Methods of Enzymatic Analysis, pp. 1704-1708. Edited by H. U. Bergmeyer. New York: Academic Press.

Carls, R. A. \& Hanson, R. S. (1971). Isolation and characterization of tricarboxylic acid cycle mutants of Bacillus subtilis. Journal of Bacteriology 106, 848855.

Cooney, P. H., Whiteman, P. F. \& Freese, E. (1977). Media dependence of commitment in Bacillus subtilis. Journal of Bacteriology 129, 901-907.

Dawes, I. W. \& Mandelstam, J. (1970). Sporulation of Bacillus subtilis in continuous culture. Journal of Bacteriology 103, 529-535.

DedONDER, R. A., LePESANT, J-A., LePESANT-KeJZlarova, J., Billault, A., Steinmetz, M. \& Kunst, F. (1977). Construction of a kit of reference strains for rapid genetic mapping in Bacillus subtilis 168 . Applied and Environmental Microbiology 33, 989-993.

Diesterhaft, M. D. \& Freese, E. (1973). Role of pyruvate carboxylase, phosphoenolpyruvate carboxykinase and malic enzyme during growth and sporulation of Bacillus subtilis. Journal of Biological Chemistry. 248, 6062-6070.

FREESE, E. (1981). Initiation of bacterial sporulation. In Sporulation \& Germination - Proceedings of the VIII International Spores Conference, pp. 1-12. Edited by H. S. Levinson, A. L. Sonenshein \& D. J. Tipper. Washington, D.C.: American Society for Microbiology.
Freese, E., Heinze, J. E. \& Galliers, E. M. (1979a). Partial purine deprivation causes sporulation of Bacillus subtilis in the presence of excess ammonia, glucose and phosphate. Journal of General Microbiology 115, 193-205.

Freese, E., Lopez, J. M. \& Freese, E. B. (1979 b). Initiation of bacterial and yeast sporulation by partial deprivation of guanine nucleotides. In Regulation of Macromolecular Synthesis by Low Molecular Weight Mediators, pp. 127-143. Edited by D. Richter \& G. Loch. New York: Academic Press.

FreEse, E., LopeZ, J. M. \& OCHI, K. (1981). Role of guanine nucleotides and of the stringent response to amino acid deprivation in the initiation of bacterial sporulation. In Microbiology - 1981, pp. 11-16. Edited by D. Schlessinger. Washington, D.C.: American Society for Microbiology.

Gallant, J. A. (1979). Stringent control in E. coli. Annual Review of Genetics 13, 393-415.

Hanson, R. S. \& Cox, D. P. (1967). Effect of different nutritional conditions on the synthesis of tricarboxylic acid cycle enzymes. Journal of Bacteriology $\mathbf{9 3}$, 1777-1787.

Henner, D. J. \& HoCH, H. A. (1980). The Bacillus subtilis chromosome. Microbiological Reviews 44, 5782.

Inima, T., Diesterhaft, M. D. \& Freese, E. (1977). Sodium effect of growth on aspartate and genetic analysis of a Bacillus subtilis mutant with high aspartase activity. Journal of Bacteriology 129, 14401447. 
KalB, V. F., JR \& Bernlohr, R. W. (1977). A new spectrophotometric assay for protein in cell extracts. Analytical Biochemistry 82, 362-371.

Kunst, F., Pascal, M., Lepesant-Kejzlarova, J., Lepesant, J.-A., Billault, A. \& Dedonder, R. (1974). Pleiotropic mutations affecting sporulation condition and the synthesis of extracellular enzymes in Bacillus subtilis 168. Biochimie 56, 1481-1489.

Lopez, J. M., Marks, C. L. \& Freese, E. (1979). The decrease of guanine nucleotides initiates sporulation of Bacillus subtilis. Biochimica et biophysica acta $\mathbf{5 8 7}$, 238-252.

Lopez, J. M., Dromerick, A. \& Freese, E. (1981 $a$ ). Response of guanosine 5 -triphosphate concentration to nutritional changes and its significance for Bacillus subtilis sporulation. Journal of Bacteriology 146, 605-613.

LOPEZ, J. M., OCHI, K. \& Freese, E. (1981 b). Initiation of Bacillus subtilis sporulation caused by the stringent response. In Sporulation \& Germination - Proceedings of the VIII International Spores Conference, pp. 128133. Edited by H. S. Levinson, A. L. Sonenshein \& D. J. Tipper. Washington, D.C.: American Society for Microbiology.

Mitani, T., Heinze, J. E. \& Freese, E. (1977). Induction of sporulation in Bacillus subtilis by decoyinine and hadacidin. Biochemical and Biophysical Research Communications 77, 1118-1125.

Nishino, T., Gallant, J., Shalit, P., Palmer, L. \& WEHR, T. (1979). Regulatory nucleotides involved in the rel function of Bacillus subtilis. Journal of Bacteriology 140, 671-679.

Ochi, K., Kandala, J. C. \& Freese, E. (1981). Initiation of Bacillus subtilis sporulation by the stringent response to partial amino acid deprivation. Journal of Biological Chemistry 256, 6866-6875.
Ogilvie, A., Wiebauer, K. \& Kersten, W. (1975). Inhibition of leucyl-transfer ribonucleic acid synthetase in Bacillus subtilis by granaticin. Biochemical Journal 152, 511-515.

OHNE, M. (1974). Regulation of aconitase synthesis in Bacillus subtilis: induction, feedback inhibition and catabolic repression. Journal of Bacteriology 117, 1295-1305.

REED, L. J. \& MukHERJEe, B. B. (1969). $\alpha$-Ketoglutarate dehydrogenase complex from Escherichia coli. Methods in Enzymology 13, 55-61.

Rhaese, H. J. \& Groscurth, R. (1976). Control of development: role of regulatory nucleotides synthesized by membranes of Bacillus subtilis in initiation of sporulation. Proceedings of the National Academy of Sciences of the United States of America 73, 331335.

Schaeffer, P., Millet, J. \& Aubert, J. P. (1965). Catabolic repression of bacterial sporulation. Proceedings of the National Academy of Sciences of the United States of America 54, 704-711.

Smith, I., Paress, P., Cabane, K. \& Dubnau, E. (1980). Genetics and physiology of the rel system of Bacillus subtilis. Molecular and General Genetics 178, 271-279.

Sterlini, J. M. \& Mandelstam, J. (1969). Commitment to sporulation in Bacillus subtilis and its relationship to development of actinomycin resistance. Biochemical Journal 113, 29-37.

TAKAHASHI, I. (1979). Catabolite repression-resistant mutants of Bacillus subtilis. Canadian Journal of Microbiology 25, 1283-1287.

Whiteman, P., Marks, C. \& Freese, E. (1980). The sodium effect of Bacillus subtilis growth on aspartate. Journal of General Microbiology 119, 493-504. 